\title{
GRUPOS DE PESQUISA DA UNIVERSIDADE FEDERAL DE MINAS GERAIS-UFMG: UMA ANÁLISE BIBLIOMÉTRICA ENTRE OS ANOS 2000-2016
}

\author{
LEANDRO CASTELLA CESAR*
}

\begin{abstract}
RESUMO
Os grupos de pesquisa vêm ganhando cada vez mais importância no processo de geração, desenvolvimento e difusão de conhecimentos científicos, tecnológicos e culturais, fornecendo suporte intelectual e estrutural, que possibilitam a qualificação das pesquisas e potencializam a geração de novos conhecimentos. Este estudo pretende apresentar as características dos grupos de pesquisa da Universidade Federal de Minas Gerais (UFMG), cadastrados no Diretório de Grupos de Pesquisa do $\mathrm{CNPq}$ (DGP/CNPq). Trata-se de uma pesquisa do tipo documental, descritiva e exploratória. Os dados foram coletados na base de dados do DGP/CNPq, com enfoque nas informações dos censos de 2000 - 2016. Os resultados indicam que a UFMG é a sétima instituição brasileira com o maior número de grupos de pesquisa cadastrados no DGP (705 em 2016), que cerca de 50\% desses grupos estão concentrados nas áreas de Ciências Humanas, da Saúde e Sociais Aplicadas, cerca de $64 \%$ desenvolvem entre uma e quatro linhas de pesquisa. Além disso, $97 \%$ dos participantes são estudantes (53\%) e pesquisadores (44\%), a maioria dos estudantes $(38 \%)$ é graduando e dos pesquisadores $(82 \%)$ é doutor e que as mulheres são a grande maioria entre os estudantes e técnicos, estão empatadas com os homens entre os pesquisadores e aparecem em menor número apenas quanto aos colaboradores estrangeiros.
\end{abstract}

PALAVRAS-CHAVE: Grupos de Pesquisa. Universidade Federal de Minas Gerais UFMG. Diretório de Grupos de Pesquisa-CNPq.

* Graduado em Direito pela Universidade FUMEC (2008). Especialista em Direito do Trabalho e Processual do Trabalho pela Faculdade Damásio (2010). Especialista em Ciência da Informação: Biblioteconomia pela Universidade Cândido Mendes (2018). Atua como Técnico na Diretoria de Produção Científica da Pró-Reitoria de Pesquisa da UFMG. Tem experiência nas áreas da Informação, Administrativa e Jurídica. Interesses de pesquisa: Produção Científica; Comunicação e Divulgação Científica; Periódicos Científicos.leandrocastella@hotmail.com 


\begin{abstract}
Research groups have been gaining more and more importance in the generation, development and diffusion of scientific, technological and cultural knowledge, providing intellectual and structural support that enables the qualification of researches and potentiate the generation of new knowledge. This study intends to present the characteristics of the research groups of the Federal University of Minas Gerais - UFMG registered in the Directory of Research Groups of the CNPq - DGP / CNPq. It is a documentary, descriptive and exploratory research. Data were collected from the DGP / CNPq database based on census data from 2000 to 2016. The results indicate that the UFMG is the seventh Brazilian institution with the largest number of research groups registered in the DGP (705 in 2016) , about $50 \%$ of these groups are concentrated in the areas of Human Sciences, Health and Applied Social Sciences, about 64\% develop between one and four lines of research, $97 \%$ of the participants are students $(53 \%)$ or researchers $(44 \%)$, the majority of the students $(38 \%)$ are graduating and the researchers $(82 \%)$ are doctor and that the women are the great majority among the students and technicians, are tied with the men among the researchers and appear in smaller numbers only among foreign employees.
\end{abstract}

KEYWORDS: Research Groups. Federal University of Minas Gerais (UFMG). Research Groups of Brazil Directory - CNPq.

\title{
1. INTRODUÇÃO
}

As universidades públicas brasileiras, via de regra, assumem papéis preponderantes na geração, no desenvolvimento e na difusão de conhecimentos científicos, tecnológicos e culturais, por meio do ensino, da pesquisa e da extensão. Tendo em mente que tais atividades, normalmente, encontram-se indissociáveis entre si, é preciso salientar que a atividade de pesquisa, mais especificamente, tem grande relevância na geração do conhecimento, motivo pelo qual será ressaltada neste estudo.

No decorrer dos anos, vê-se uma contínua transformação na forma de produção do conhecimento, que já não é mais percebida como uma atividade isolada do pesquisador. A geração do conhecimento tornou-se mais complexa, de forma que aquele pesquisador que outrora realizava seus estudos individualmente, depara-se com a importância/necessidade de se aliar a outros pesquisadores para ampliar a geração de conhecimento.Daí surge o estímulo a formação de grupos de pesquisa. (MARAFON, 2008 ). 
Os grupos de pesquisa, no Brasil, começaram a se consolidar na década de 90 , quando se estabeleceu a ideia de que a geração do conhecimento se dá através de um empreendimento coletivo e não apenas cognitivo. (BACKERS et al., 2009). Nesse período, foram criadas políticas governamentais de motivação ao novo modelo de organização, como, por exemplo, a criação, em 1993, do Diretório de Grupos de Pesquisa (DGP) do Conselho Nacional de Desenvolvimento Científico e Tecnológico (CNPq), que, em sua primeira versão, possuía 99 instituições e 4.402 grupos de pesquisa cadastrados. (RAPINI, 2007).

Nas palavras de Erdmann e Lanzoni (2008, p. 317):

os grupos de pesquisa fornecem o suporte necessário de infraestrutura para as atividades de pesquisa, a oportunidade de trabalho integrado e a possibilidade de incremento do potencial em pesquisa.

Esses grupos têm papel preponderante em grande parte das investigações realizadas na atualidade e contribuem significativamente para a formação de inúmeros pesquisadores. Por este motivo, podemse tornar um atributo diferencial na formação dos estudantes/pesquisadores voltados para a investigação científica, proporcionando uma educação complementar de qualidade. (MARAFON, 2008).

Através do DGP, é possível cadastrar diversas informações sobre os grupos e os trabalhos por eles desenvolvidos por meio do formulário do grupo. Tal formulário é um questionário eletrônico padronizado para que os líderes preencham as informações sobre suas equipes. Nele é possível informar dados sobre: a) identificação do grupo; b) o endereço/contato dos seus membros; c) as repercussões dos trabalhos e participações em redes; d) as linhas de pesquisa e especialidades do conhecimento; e) os recursos humanos (pesquisadores, estudantes, técnicos e colaboradores estrangeiros) e seus indicadores (formação acadêmica); f) as instituições parceiras; e g) a estrutura (equipamentos e softwares utilizados).

As referidas informações são inventariadas pelo DGP e constituem riquíssimas bases de dados que, por estarem disponíveis, podem ser utilizadas como importantes fontes de informação pela comunidade científica, possibilitando o intercâmbio de informações entre os pesquisadores. (ARAÚJO, 2009).

Diante desse breve panorama histórico e conceitual, é possível verificar a importância dos grupos de pesquisa no processo de geração, desenvolvimento e difusão de conhecimentos científicos, tecnológicos e 
culturais. Isso porque,fornecem suporte intelectual e estrutural, que possibilitam a qualificação das pesquisas realizadas e, consequentemente, potencializam a geração de novos conhecimentos.

Dessa forma, este estudo objetiva realizar um diagnósticode como os grupos de pesquisa UFMG se organizam. Isso ocorrepor meio de análise dos dados disponíveis no DGP, entre os anos de 2000 e 2016, traçando-se, assim, o seu perfil institucional.

\section{METODOLOGIA}

Realizou-se uma pesquisa do tipo documental, descritiva e exploratória. Esta almejoumapear o perfil dos grupos de pesquisa da UFMG.

A principal fonte de dados utilizada foi o Diretório de Grupos de Pesquisa do $\mathrm{CNPq}^{1}$, disponível na Plataforma Lattes ${ }^{2}$. Os dados sobre os grupos de pesquisa foram coletados a partir das informações dos censos ${ }^{3}$ do DGP, dos anos de 2000, 2002, 2004, 2006, 2008, 2010, 2014 ${ }^{4}, 2016$, utilizando-se, para tanto, os dados apresentados: a) no Painel do DGP; b) na Súmula Estatística; e c) nas Séries Históricas.

Apesar de trazer, sempre que possível, uma análise histórica do corpus, procurou-se dar maior ênfase ao obtido no censo de 2016, o último divulgado até o momento. Primeiramente, apresentou-sebrevemente 0 cenário dos grupos de pesquisa brasileiros como um todo, para, então, depois demonstrar o perfil da UFMG e traçar eventuais comparativos entre os dois cenários.

Para análise dos dados, criou-se um banco de dados, utilizando-se o software Microsoft Excel, onde os dados foram compilados, organizados e tratados, de forma a otimizar o seu tratamento e análise. Os dados foram coletados no decorrer do primeiro semestre de 2018.

\footnotetext{
${ }^{1}$ http://lattes.cnpq.br/web/dgp

${ }^{2}$ http://lattes.cnpq.br/

${ }^{3}$ São "fotografias" da base corrente do DGP, tiradas numa frequência quase sempre bienal para realizar um censo da capacidade instalada de pesquisa no país e apresentam informações quantitativas sobre os grupos de pesquisa em suas diversas dimensões (CNPQ, 2018).

${ }^{4}$ O CNPq não realizou o censo no ano de 2012, motivo pelo qual os dados referentes ao referido ano não foram objeto de análise.
} 


\section{RESULTADOS E DISCUSSÃO}

Conforme antecipado anteriormente, neste item serão abordados: a) primeiramente as características dos grupos de pesquisa brasileiros, apresentando, de forma sucinta, seus principais aspectos;b) em seguida, demonstrar as características dos grupos de pesquisa da UFMG, objetivando traçar o seu perfil institucional, ao mesmo tempo em que se faz um paralelo com o perfil brasileiro.

\subsection{Grupos de pesquisa brasileiros: breve panorama}

De acordo com o CNPq, é possível verificar um crescimento considerável no número de grupos de pesquisa cadastrados. Em 2016, data do último censo publicado, existiam 37.640 grupos cadastrados, o que corresponde a um aumento de cerca de $79 \%$, se comparados com os dados de 10 anos atrás (21.024, em 2006).

Figura 1 - Número de grupos de pesquisa brasileiros cadastrados por ano/censo (2000-2016).

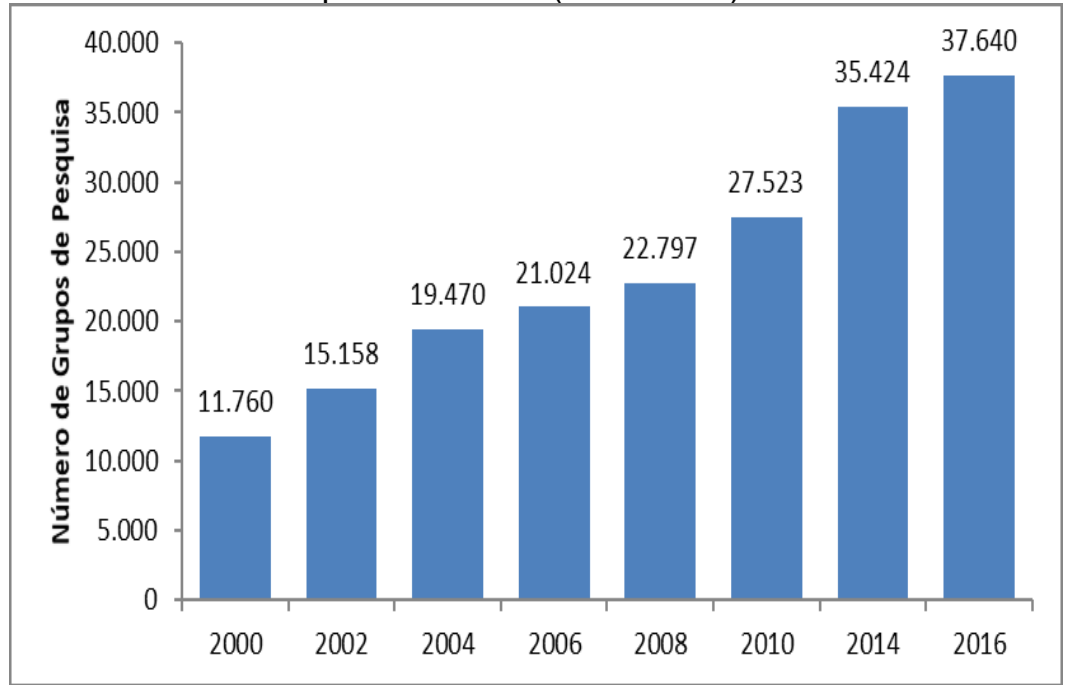

FONTE: Elaborada pelo autor. 
Embora o número de grupos de pesquisa cadastrados no DGP venha aumentando a cada ano, verifica-se uma grande oscilação na taxa de crescimento. No censo de 2016, foi registrada a menor taxa de crescimento entre 2000 e2016, com um aumento de cerca de $6 \%$, apenas.

Figura 2 - Taxa de crescimento dos grupos de pesquisa brasileiros cadastrados por ano/censo (2002- 2016).

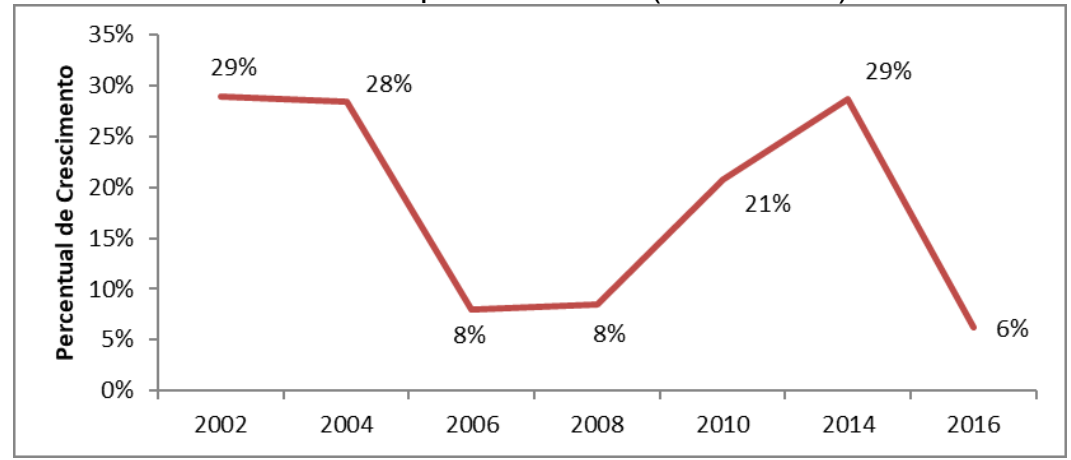

FONTE: Elaborada pelo autor.

De acordo com o mapa disponível no Painel do DGP, o maior número de grupos de pesquisa está concentrado nas regiões Sudeste e Sul do Brasil, com destaque para: São Paulo (7.447), Rio de Janeiro (4.360), Rio Grande do Sul (3.601), Minas Gerais (3.477) e Paraná (1.174). Embora a grande maioria dos grupos seja das regiões Sudeste e Sul, é importante salientar que essa diferença vem sendo mitigada, demonstrando certa tendência àdescentralização. Enquanto que, em 2000, essas regiões concentravam $77 \%$ do total de grupos brasileiros, em 2016 esse número caiu para $66 \%$. A região Norte, por exemplo, que em 2000 detinha $3 \%$, em 2016 passou a concentrar $6 \%$ do total de grupos. 0 mesmo aconteceunas regiões Nordeste e Centro-Oeste que, no mesmo período, passaram de $15 \%$ e $5 \%$ para $21 \%$ e $8 \%$, respectivamente. 
Figura 3 - Grupos de pesquisa por Unidade da Federação (censo 2016).

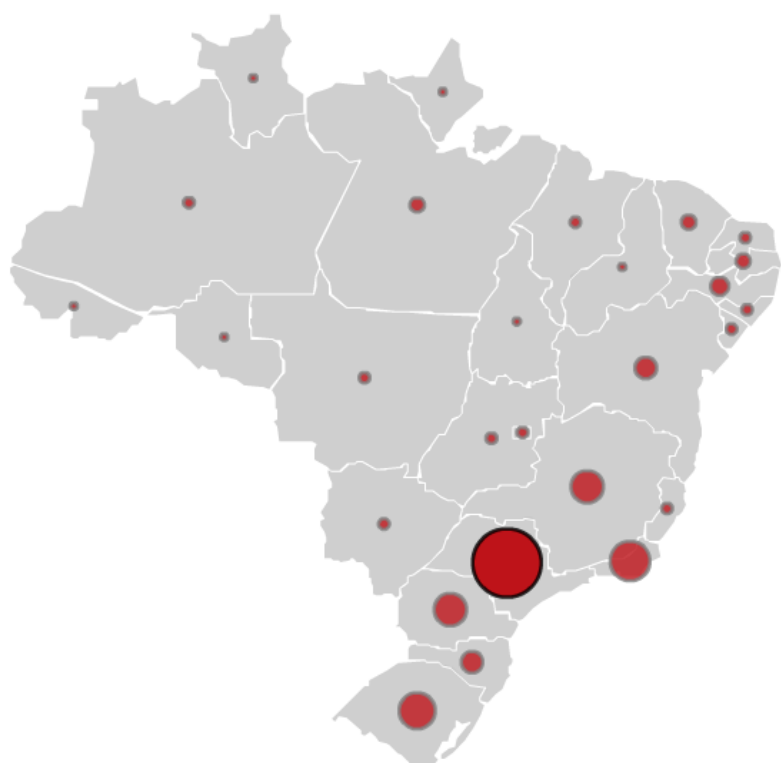

FONTE: Diretório de Grupos de Pesquisa - CNPq, 2016.

Verifica-se na Figura 3 que as Instituições ${ }^{5}$ com maior número de grupos de pesquisa, destacam-se a USP, UFRJ, UNESP, UFRGS, UFF, UNICAMP, UFMG e UFSC.

${ }^{5}$ Foram consideradas as Instituições até o percentual referente à UFMG. 
Figura 4 - Percentual de grupos de pesquisa por Instituição (Censo, 2016).

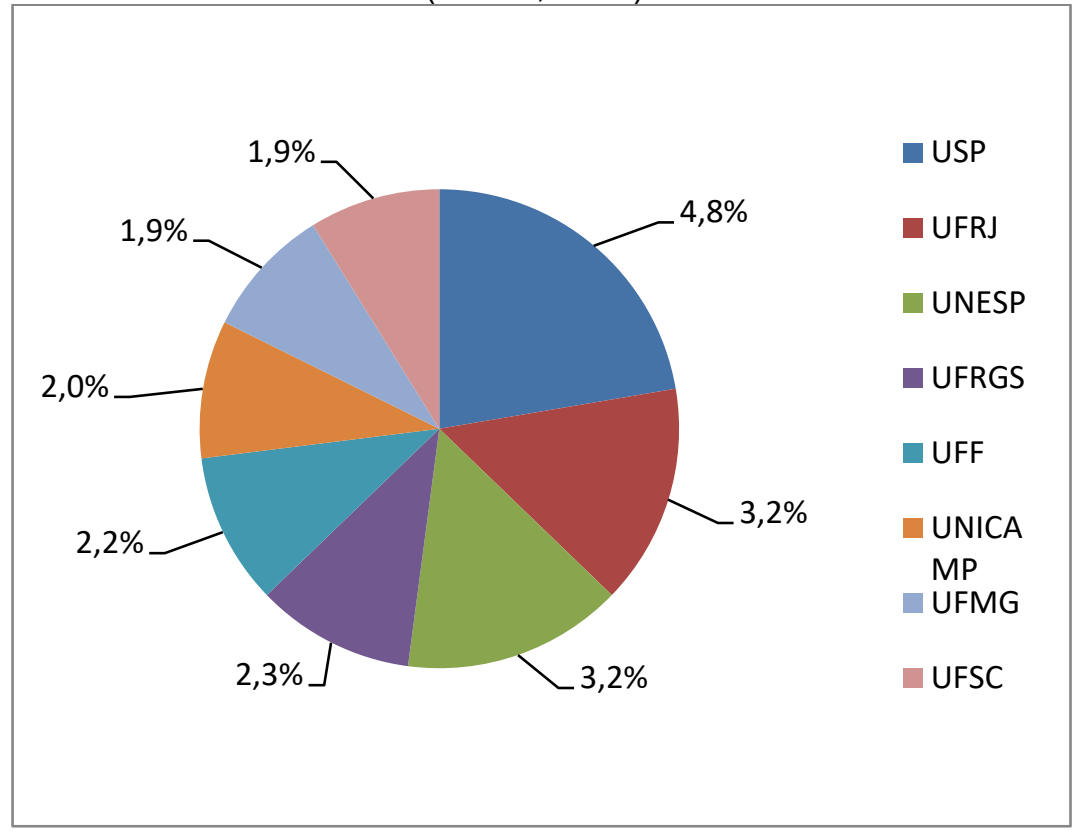

FONTE: Elaborada pelo autor.

No que tange à distribuição dos grupos de pesquisa quanto às áreas do conhecimento, verifica-se que cerca de $50 \%$ estão distribuídos entre as áreas de Ciências Humanas, da Saúde e Sociais Aplicadas, com destaque para as Ciências Humanas, que possuem $22 \%$ do total. 
Figura 5 - Percentual de grupos de pesquisa brasileiros por grande área (Censo, 2016).

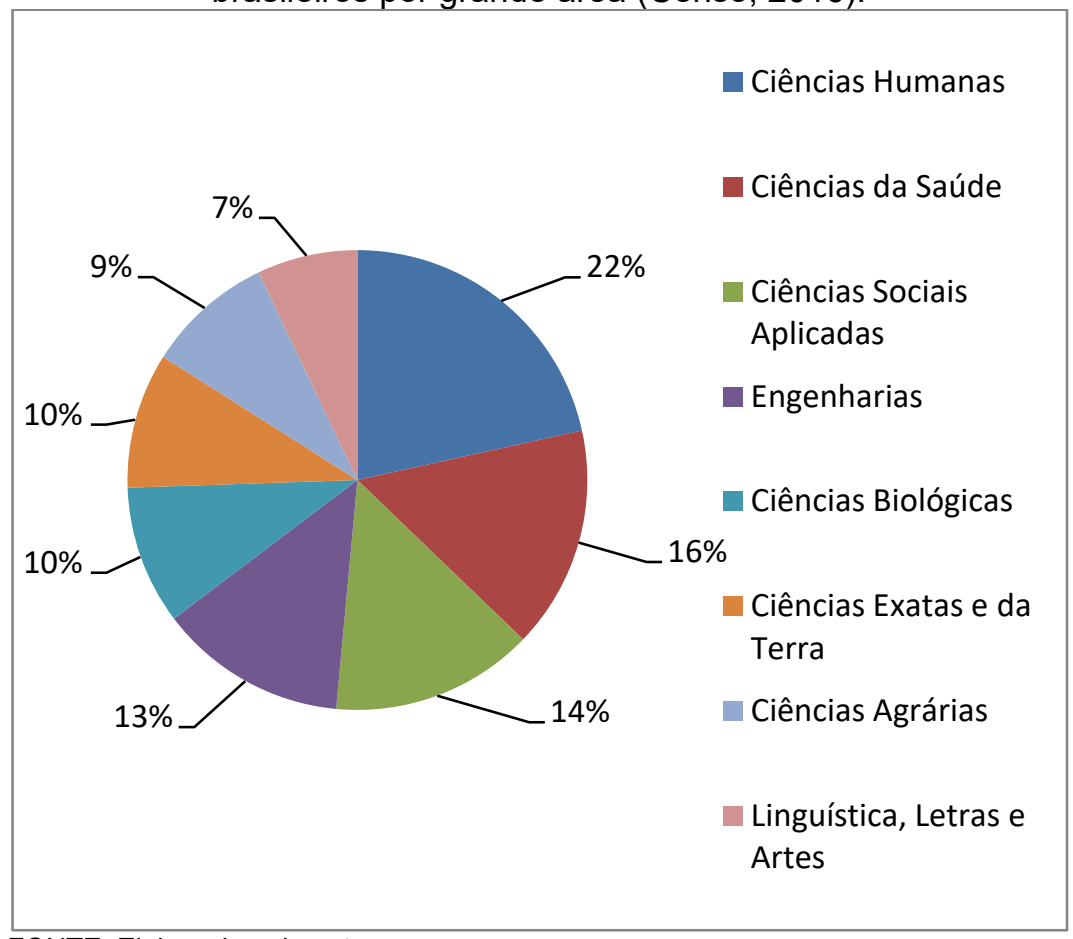

FONTE: Elaborada pelo autor.

Analisando-se o número de linhas de pesquisa por grupos de pesquisa brasileiros, verifica-se que, cerca de $70 \%$ dos grupos, possuem entre uma e quatro linhas de pesquisa, sendo o mais frequente duas ou três linhas (cerca de 40\%). 
Figura 6 - Percentual de linhas de pesquisa por grupos - Brasil (Censo, 2016).

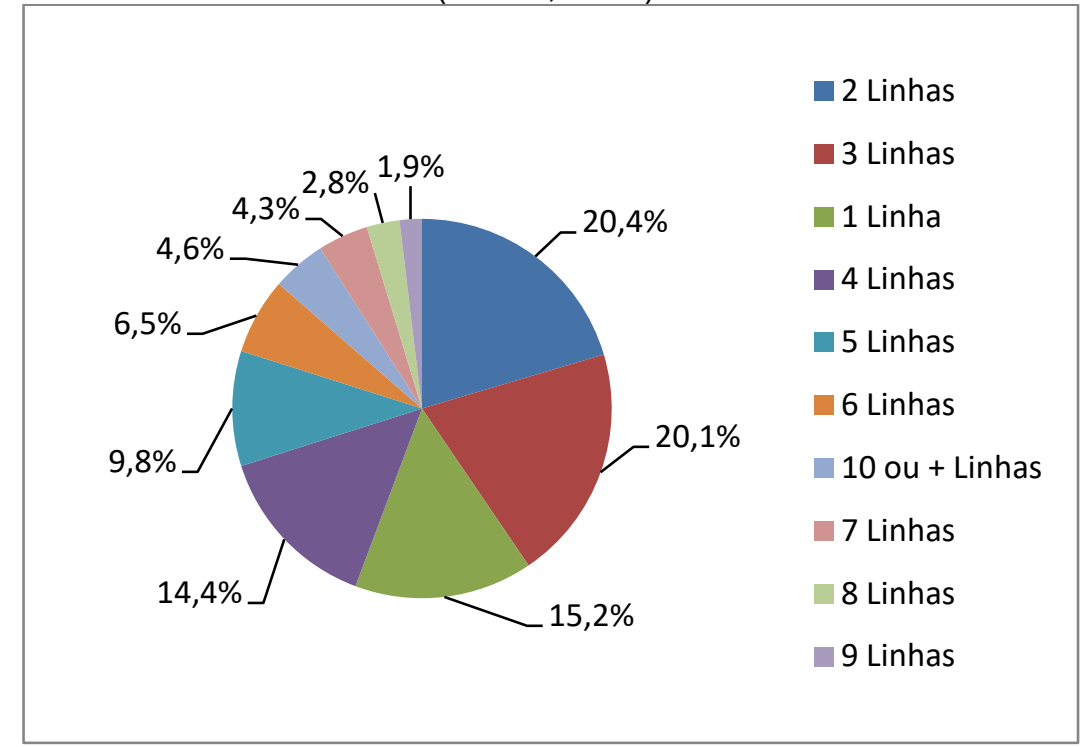

FONTE: Elaborada pelo autor.

Finalizando esse breve panorama nacional dos grupos de pesquisa cadastrados no DGP, faz-se necessário frisar que o DGP divide os membros integrantes dos grupos de pesquisa em quatro categorias, quais sejam: 1) pesquisadores; 2) estudantes; 3) técnicos e 4) colaboradores estrangeiros. Conforme demonstrado na Figura 7, de acordo com os dados do censo de 2016 do DGP, os grupos de pesquisa brasileiros são compostos, em sua maioria, por estudantes $(60 \%)$ e pesquisadores (36\%), correspondendo a cerca de $96 \%$ de todo o recurso humano envolvido. 
Figura 7 - Percentual de membros dos grupos de pesquisa por categoria (Censo, 2016) - Brasil.

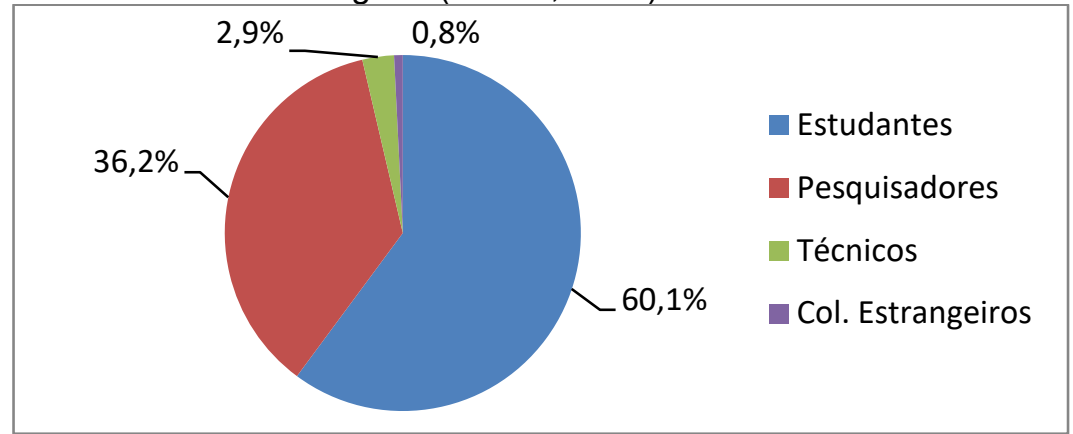

FONTE: Elaborada pelo autor.

Observa-se que, no início dos anos 2000, o número de estudantes e pesquisadores eram bem próximos.Contudo, percebese uma tendência para o aumento na proporção de estudantes versuspesquisadores. Nota-se, ainda, uma discreta participação de técnicos e colaboradores estrangeiros ${ }^{6}$.

Figura 8 - Número de membros dos grupos de pesquisa por categoria eano/censo - Brasil.

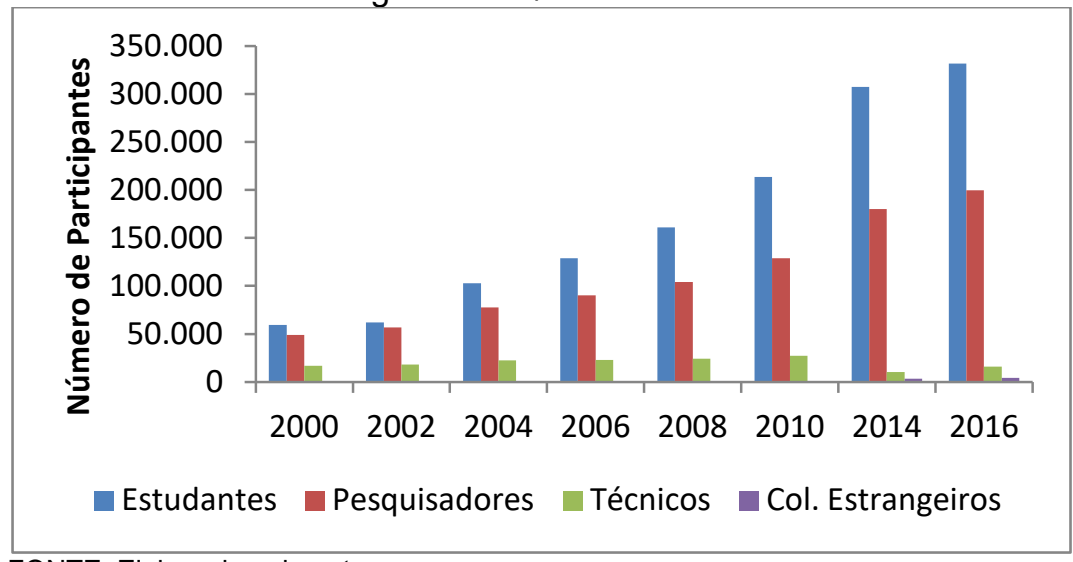

FONTE: Elaborada pelo autor.

${ }^{6}$ Os dados referentes aos colaboradores estrangeiros só aparecem nos censos a partir do ano de 2014. 
Tendo em vista que os estudantes e os pesquisadores se destacam, numericamente, na composição dos grupos de pesquisa, outra análise interessante a se fazer é aquela que se refere à sua distribuição por gênero. De acordo com os dados apresentados na Figura 9, é possível verificar que homens e mulheres estão praticamente empatados quando se trata do número de pesquisadores. Entretanto, ao analisar o número de estudantes, torna-se visível a supremacia do número de mulheres, que corresponde a cerca de $60 \%$ do total de integrantes dos grupos de pesquisa brasileiros, de acordo com o último censo realizado (2016).

Figura 9 - Percentual de pesquisadores e estudantes por gênero censo 2016.

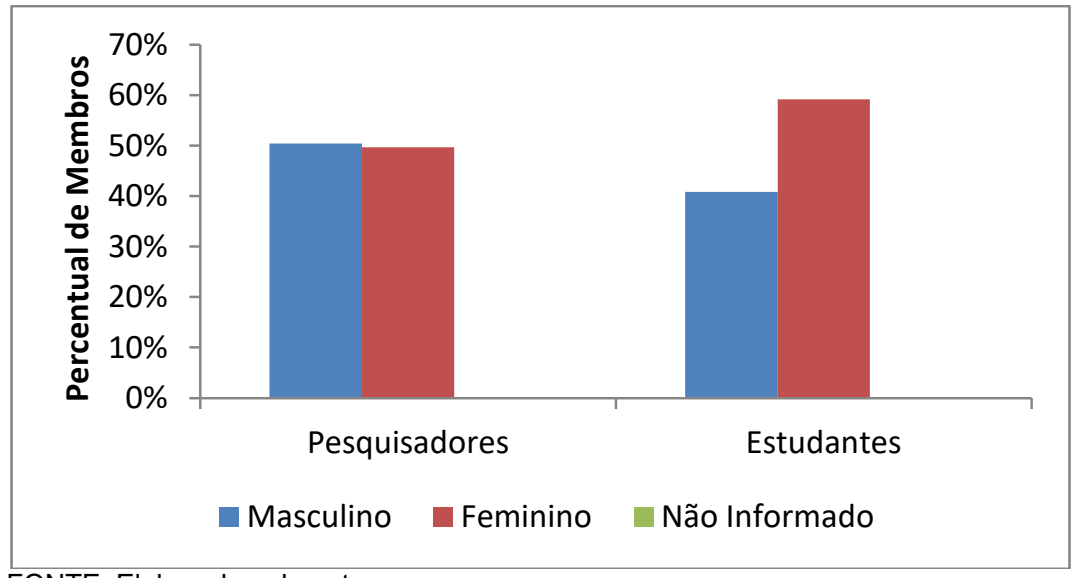

FONTE: Elaborada pelo autor.

É necessário destacar, ainda, o crescimento da presença feminina, tanto no que diz respeito ao número de pesquisadores quanto no de estudantes. Na Figura 10, é possível constatar como o número de mulheres cresceu, chegando quase a empatar com o número de homens, em 2014, e ficando muito próximo em 2016. Já na 11, é possível observar que as estudantes já eram maioria, desde o início da década e estão aumento cada vez mais. 
Figura 10 - Evolução do número de pesquisadores por gênero.

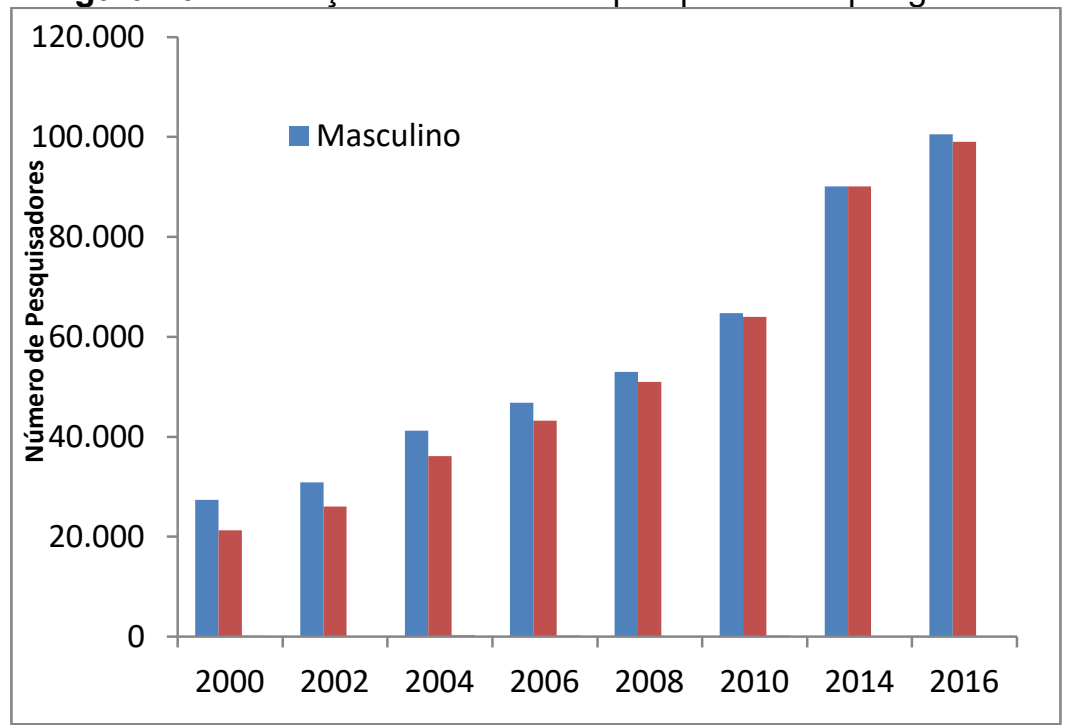

FONTE: Elaborada pelo autor.

Figura 11 - Evolução do número de estudantes por gênero.

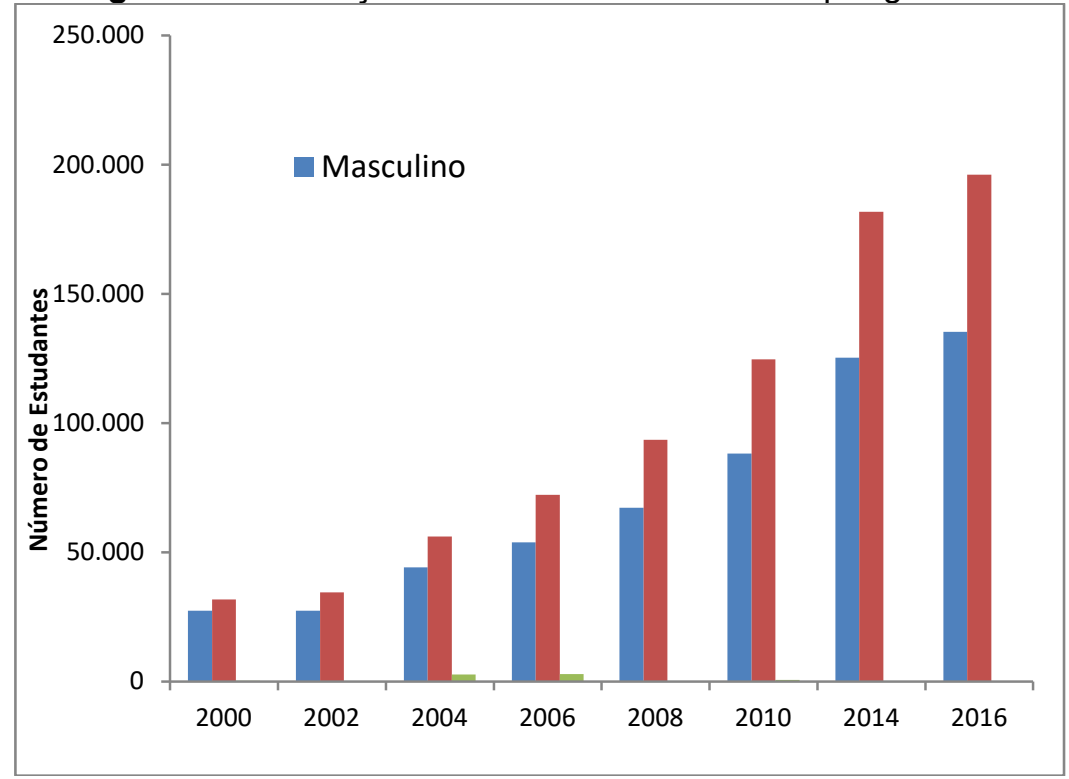

FONTE: Elaborada pelo autor. 


\subsection{Perfil dos grupos de pesquisa da UFMG}

Traçado um breve panorama dos grupos de pesquisa brasileiros, passa-se, agora, a analisar as características dos grupos de pesquisa da UFMG, referenciando-se, sempre que possível, paralelos entre os dois perfis.

\subsubsection{Evolução dos grupos de pesquisa}

Diferentemente do panorama nacional, os grupos de pesquisa da UFMG cadastrados no DGP demonstram certa oscilação na sua evolução quantitativa. Eles apontam um crescimento de cerca de $9 \%$, contra $79 \%$ do perfil brasileiro, nos últimos 10 anos. Note-se que houve, inclusive, uma queda no número de grupos nos anos de 2008 e 2016.

Figura 12 - Número de grupos de pesquisa da UFMG cadastrados por ano/censo (2000-2016).

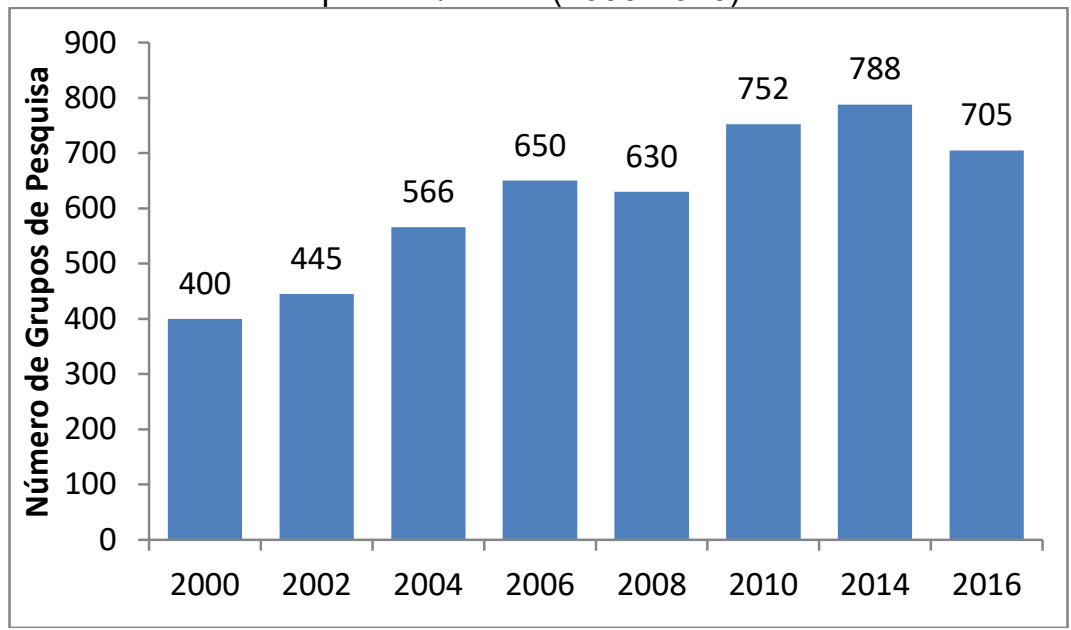

FONTE: Elaborada pelo autor.

Quanto à taxa de crescimento, verifica-se, por meio da Figura 13 que, apesar das pequenas variações, a UFMG reflete a mesma tendência nacional. 
Figura 13 - Comparativo entre as taxas de crescimento UFMG x Brasil - (2002-2016).

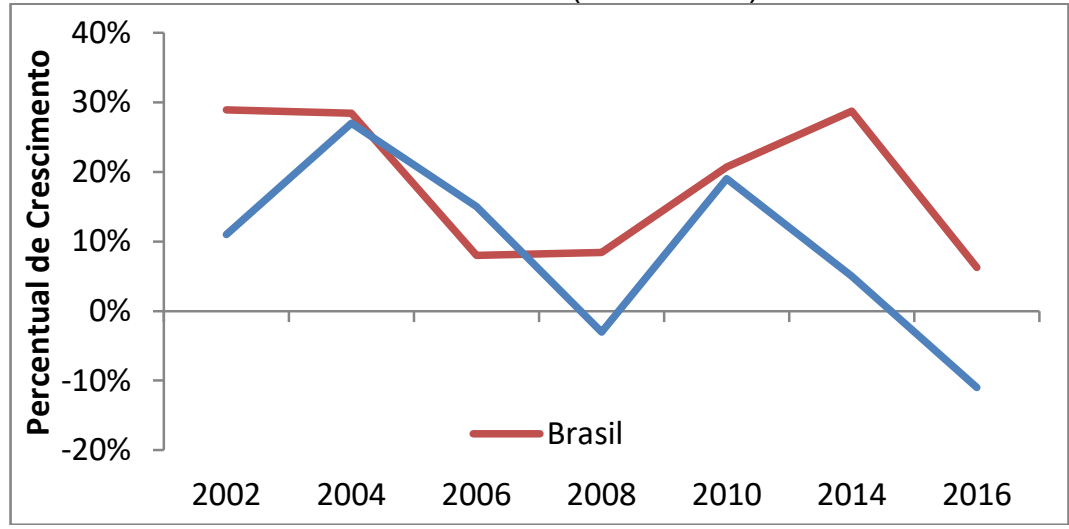

FONTE: Elaborada pelo autor.

Esses dados, conjugados com o direcionamento das ações implementadas pela UFMG nos últimos anos, indicam uma possível mudança na política de criação de grupos de pesquisa.Isso pois se deixa de incentivar tão somente a quantidade, passando a dar maior ênfase à qualidade dos grupos de pesquisa criados e/ou mantidos.

De acordo com os últimos documentos do Plano de Desenvolvimento Institucional - (PDI) (UNIVERSIDADE FEDERAL DE MINAS GERAIS, 2013, 2018) a UFMG tem buscado: a) estimular a qualificação dos grupos de pesquisa; b) disseminar a prática do estabelecimento de metas de impacto; c) estimular o aumento qualitativo da produção científica em veículos de maior impacto e visibilidade; d) incentivar a articulação entre grupos de pesquisa com afinidades temáticas ee) estimular a consolidação de grupos de pesquisa emergentes em áreas de interesse estratégico; dentre outras ações.

Importante ressaltar, também, que, recentemente, o Conselho de Ensino, Pesquisa e Extensão aprovou nova resolução que normatiza a criação de grupos de pesquisa no âmbito da UFMG (UNIVERSIDADE FEDERAL DE MINAS GERAIS, 2019). Referida resolução torna mais rígida a criação de grupos de pesquisa na UFMG, passando a exigir, por exemplo, que a solicitação passe pelo crivo de duas instâncias institucionais (Câmara Departamental e Congregação da Unidade) e, ainda, que os líderes tenham, preferencialmente, a titulação de doutor. 
Nota-se que tais ações, mesmo que se mostrem incipientes e que não tragam grandes mudanças, em um primeiro momento, são passos importantes no caminho da instituição de uma nova cultura de qualificação dos grupos de pesquisa e poderão implicar um retorno positivo emmédio e longo prazo.

\subsubsection{Grupos de pesquisa por área do conhecimento}

De acordo com os dados do censo, em 2016, a UFMG tinha 705 grupos de pesquisa cadastrados, distribuídos entre as oito áreas do conhecimento. Assim como no panorama nacional, cerca de $50 \%$ dos grupos da UFMG estão concentrados nas áreas Ciências Humanas, da Saúde e Sociais Aplicadas. Entretanto, nauniversidade, as Ciências da Saúde figuram ao lado das Ciências Humanas, com $17 \%$ de representatividade para cada.

Figura 14 - Percentual de grupos de pesquisa da UFMG por grande área (Censo, 2016).

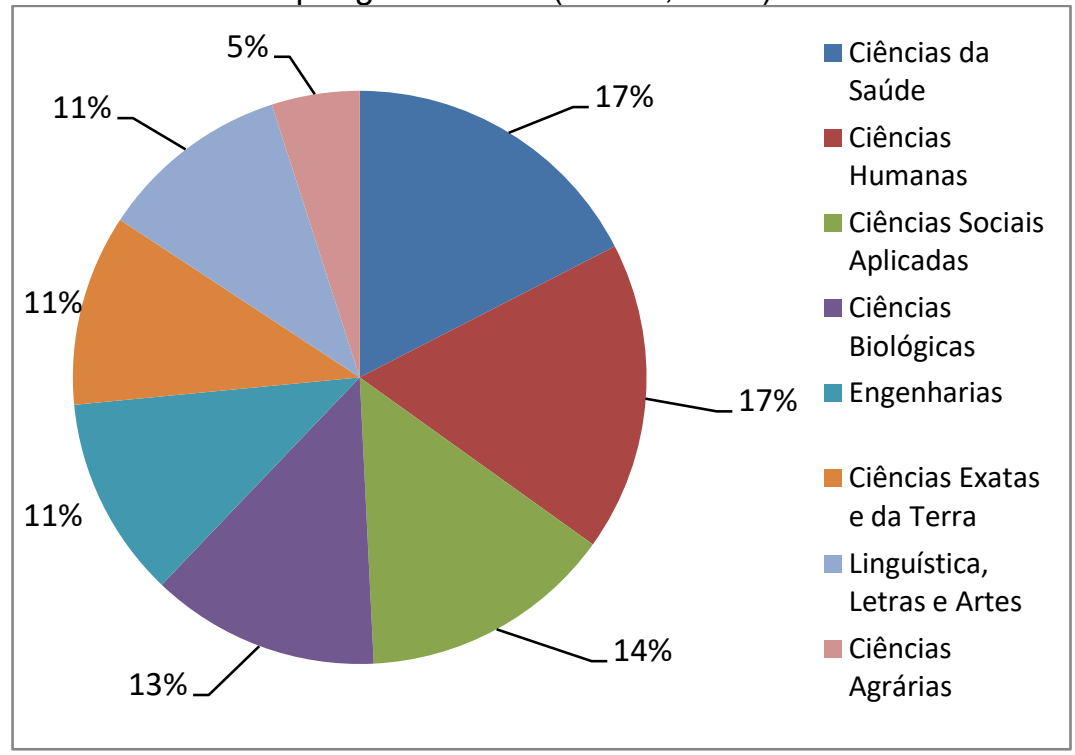

FONTE: Elaborada pelo autor.

Verifica-se que os grupos de pesquisa cadastrados da UFMG possuem maior representatividade, quando comparadosao perfil brasileiro, nas áreas de Ciências da Saúde, Biológicas, Exatas e da Terra e Linguística, Letras e Artes, em detrimento das áreas de Humanas, Engenharias e Agrárias. 
Figura 15 - Percentual de grupos de pesquisa por grande área Brasil x UFMG (Censo, 2016).

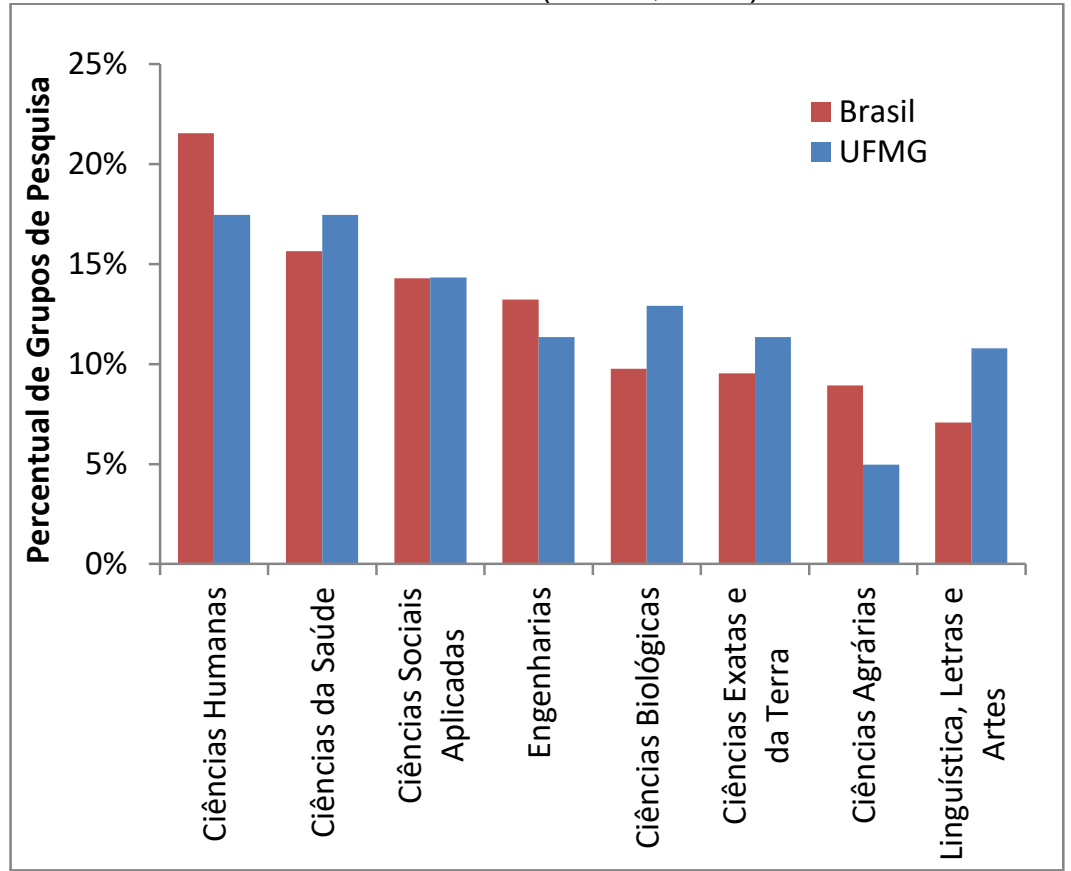

FONTE: Elaborada pelo autor.

Cabe ressaltar que os números apresentados são resultado de uma análise quantitativa, que não leva em conta dados como, por exemplo, a proporção de docentes por área do conhecimento da instituição. Assim, há a possibilidade de que, em áreas que possuam número maior de docentes, haja, naturalmente, maior quantidadede grupos de pesquisa cadastrados. No gráfico a seguiré possível verificar um comparativo entre os percentuais de docentes e de grupos de pesquisa da UFMG, por área do conhecimento. 
Figura 16 - Percentual de docentes $x$ grupos de pesquisa por grande área - UFMG (censo 2016).

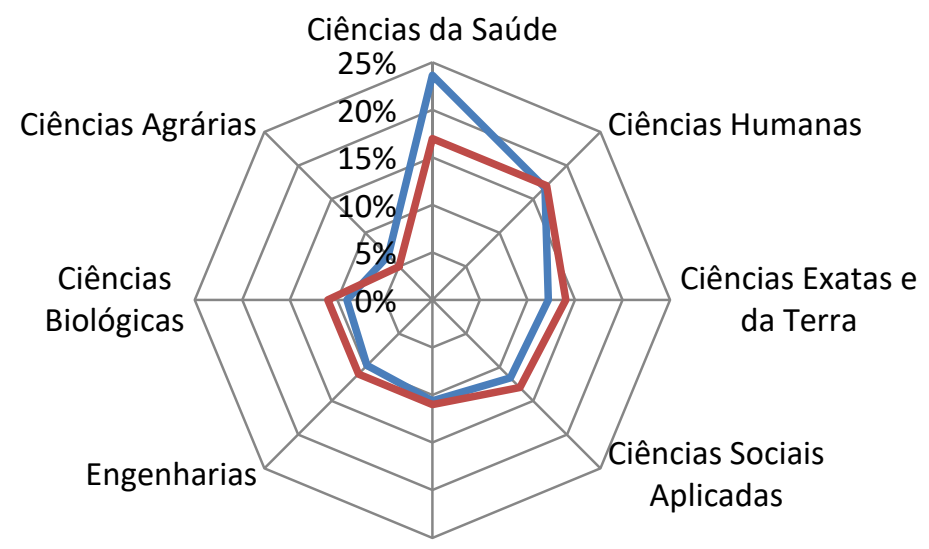

Linguística, Letras

e Artes

\% Docentes UFMG — $\quad$ Grupos de Pesquisa

FONTE: Elaborada pelo autor.

3.2.3 Grupos de pesquisa por linhas de pesquisa

Analisando-se o número de linhas de pesquisa por grupos, nota-se que, cerca de $64 \%$ possuem entre uma e quatro linhas de pesquisa. Em termos comparativos, verifica-se que, na UFMG (Figura 17), o número de grupos de pesquisa que desenvolve apenas uma linha de pesquisa está muito próximo do percentual daqueles que desenvolvem duaslinhas (menos de 1\% de diferença), enquanto que, no perfil brasileiro, (Figura 6) essa diferença é de cerca de $5 \%$. 
Figura 17 - Percentual de linhas de pesquisa por grupos - UFMG.

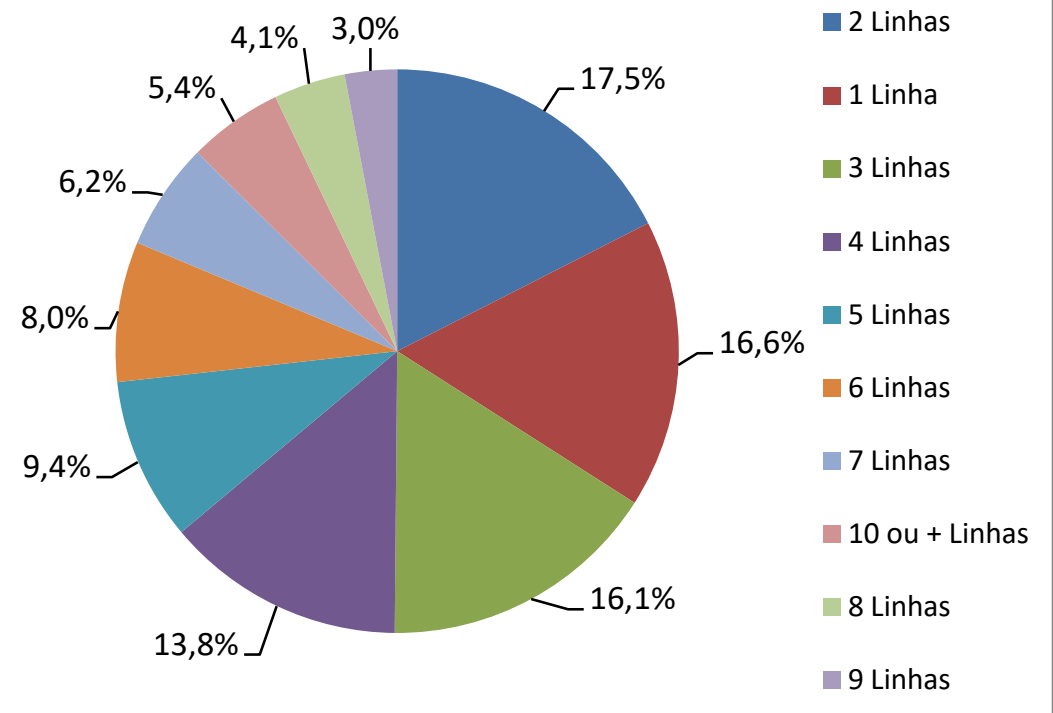

FONTE: Elaborada pelo autor.

Em se tratando de linhas de pesquisa em relação às grandes áreas do conhecimento, é importante ressaltar algumas peculiaridades da UFMG em relação ao perfil brasileiro. OBrasil (Figura 5) possui maior número nas grandes áreas de Ciências Humanas $(17,8 \%)$, Engenharias ${ }^{7}(16 \%)$ e Ciências da Saúde $(15,1 \%)$, respectivamente, enquanto que a UFMG (Figura 18) demonstra destaque nas áreas de Ciências da Saúde (19,3\%), Ciências Humanas (15,7\%), Ciências Exatas e da Terra ${ }^{10}(15,2 \%)$ e Ciências Biológicas (14,4\%). Chama-se a atenção para a área de Ciências Agrárias, em que a UFMG está muito abaixo da média brasileira e para a área de Linguística, Letras e Artes, em que a UFMG se destaca em relação à média brasileira.

\footnotetext{
${ }^{7}$ O Diretório de Grupos de Pesquisa do CNPq apresenta os dados relacionados às linhas de pesquisa ligadas à computação de forma diferente de acordo com a base pesquisada. Para o painel do DGP (fonte consultada para levantar os dados referentes ao Brasil) a computação está junto com Engenharias e para a base corrente do DGP (fonte consultada para levantar os dados da UFMG) a computação está abarcada nas Ciências Exatas e da Terra.
} 
Figura 18 - Percentual de linhas de pesquisa em relação à grande área do conhecimento.

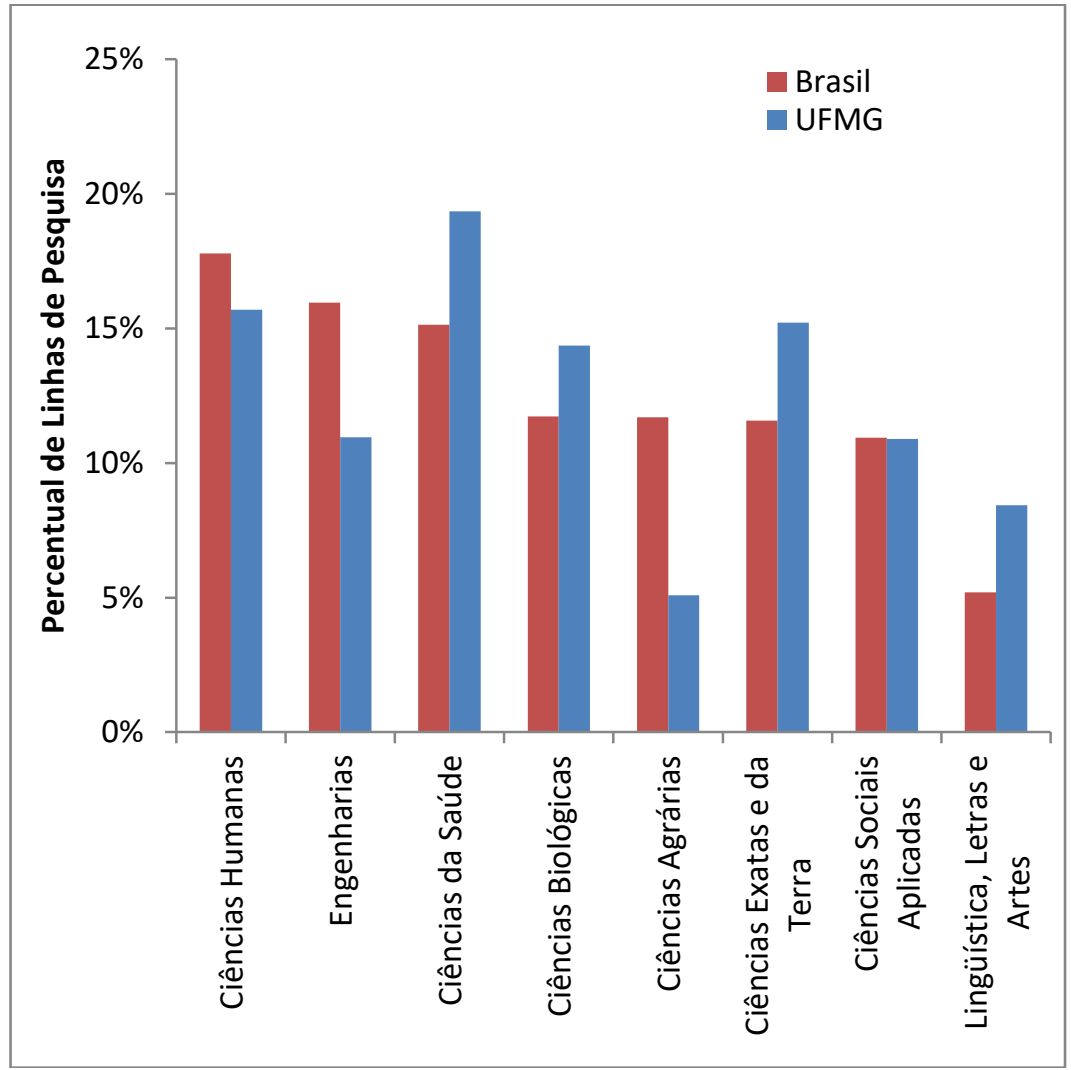

FONTE: Elaborada pelo autor.

3.2.4 Recursos humanos dos grupos de pesquisa

Assim como no perfil brasileiro, os grupos de pesquisa da UFMG são, majoritariamente, compostos por estudantes e pesquisadores, correspondendo a $97 \%$ do total de participantes (com base no censo 2016 do DGP). Entretanto, embora ainda continuem sendo a maioria (com 53\% de estudantes), a diferença entre o número de estudantes e o de pesquisadores é menor no perfil verificado na UFMG. Enquanto que, no Brasil (Figura 7), a diferença fica em, cerca de $14 \%(60 \%$ estudantes e $36 \%$ pesquisadores), na UFMG (Figura 19) essa diferença cai para $9 \%$ (53\% estudantes e $44 \%$ pesquisadores). 
Nota-se que, também na UFMG, o número de técnicos e colaboradores esrangeiros é muito baixo, atingindo, apenas, $3 \%$ do total de participantes.

Figura 19 - Percentual de membros dos grupos de pesquisa por categoria (Censo, 2016) - UFMG.

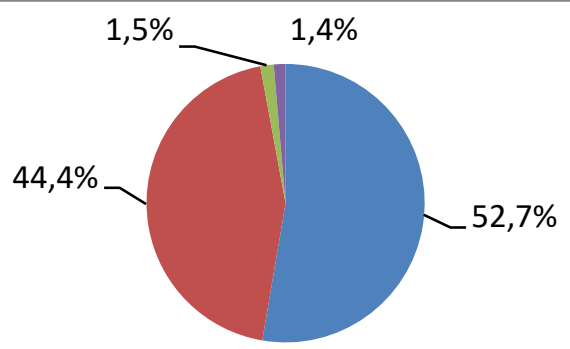

Estudantes

Pesquisadores

Técnicos

Col. Estrangeiros

FONTE: Elaborada pelo autor.

Verifica-se que, com exceção do ano de 2002, o número de estudantes sempre foi, consideravelmente, maior que o número de pesquisadores nos grupos de pesquisa da UFMG. Valeressaltar que houve uma queda relevanteno número de técnicos envolvidos a partir do censo de 2014.

Figura 20 - Número de membros dos grupos de pesquisa por categoria por ano/censo - UFMG.

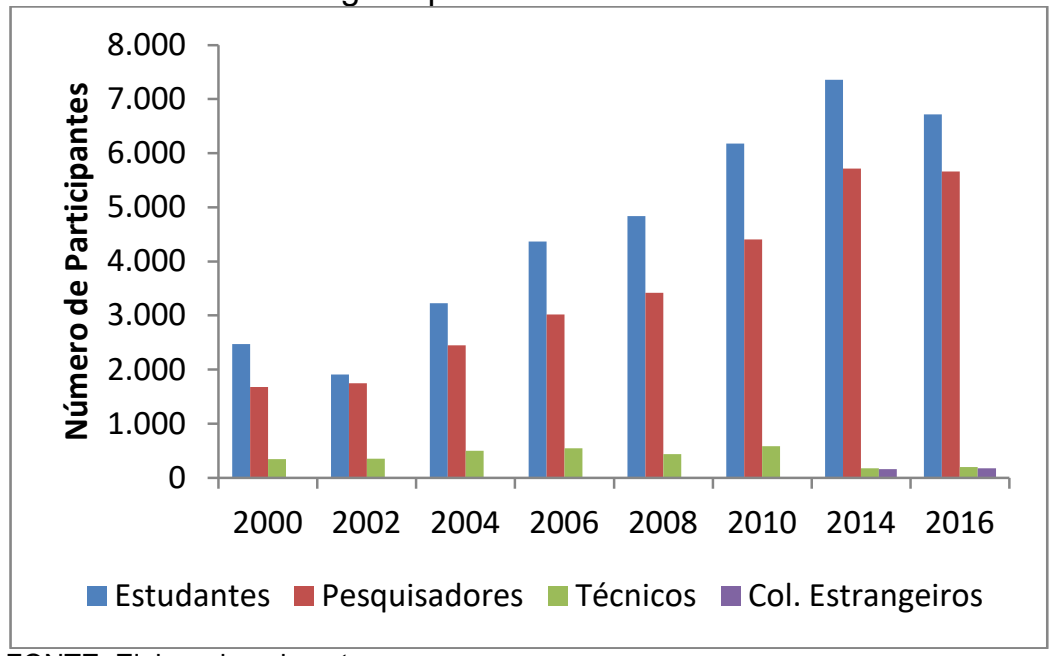

FONTE: Elaborada pelo autor. 
Outra característica que merece ser ressaltada na comparação entre o perfil brasileiro e o da UFMG é que naquele (Figura 8) o número de estudantes e pesquisadores era bem próximo no início da década de 2000. Esse número foi se distanciando com o passar do tempo, fazendo com que a disparidade aumentasse cada vez mais em favor do número de estudantes, enquanto o perfil da UFMG mostra característica diferente (Figura 20).Apesar disso,o número de estudantes já era consideravelmente maior no início dos anos 2000 e, embora tenha crescido até 2010 (com exceção de 2002), a partir de 2014 começou a dar sinais de queda, que se tornaram muito nítidos em 2016, demonstrando uma tendência no aumento de pesquisadores integrantes dos grupos de pesquisa.

No que tange à titulação dos participantes, com base nos dados do censo de 2016, verifica-se, em síntese, que a maioria dos estudantes é graduando (38\%), dos pesquisadores é doutor $(82 \%)$, dos técnicos é graduado (34\%) e dos colaboradores estrangeiros é doutor (89\%). Na figura que segueé possível verificar os dados mais detalhadamente.

Figura 21 - Percentual de membros dos grupos de pesquisa por titulação (censo 2016) - UFMG.

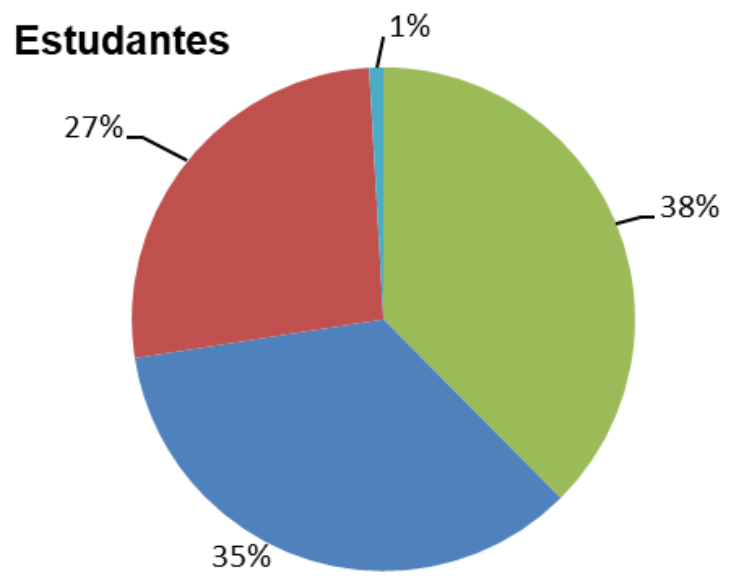

- Graduandos

- Doutorandos

- Mestrandos

- Outros 


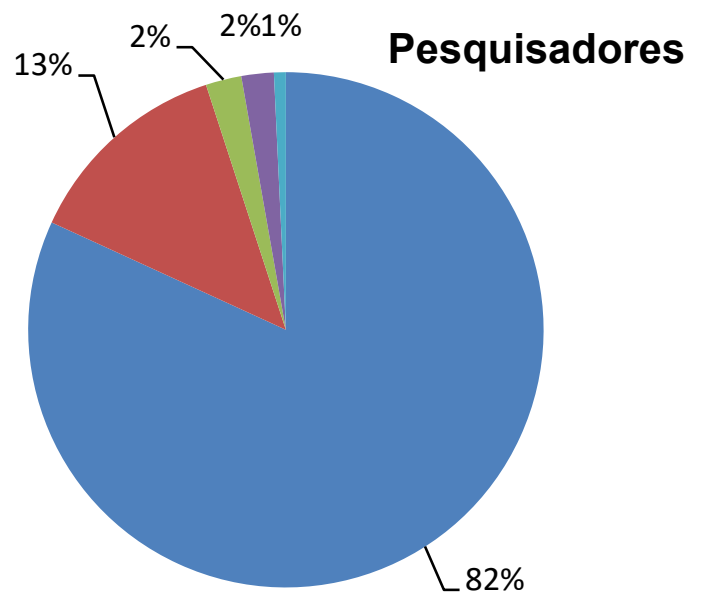

Doutorado $\square$ Mestrado $\quad$ Graduação
Especialização Outros

\section{Técnicos $7 \%$}

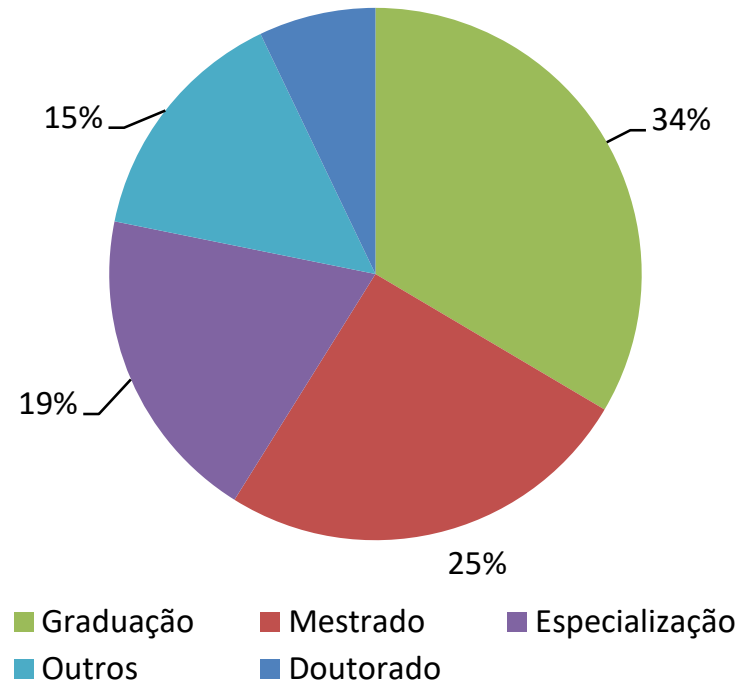




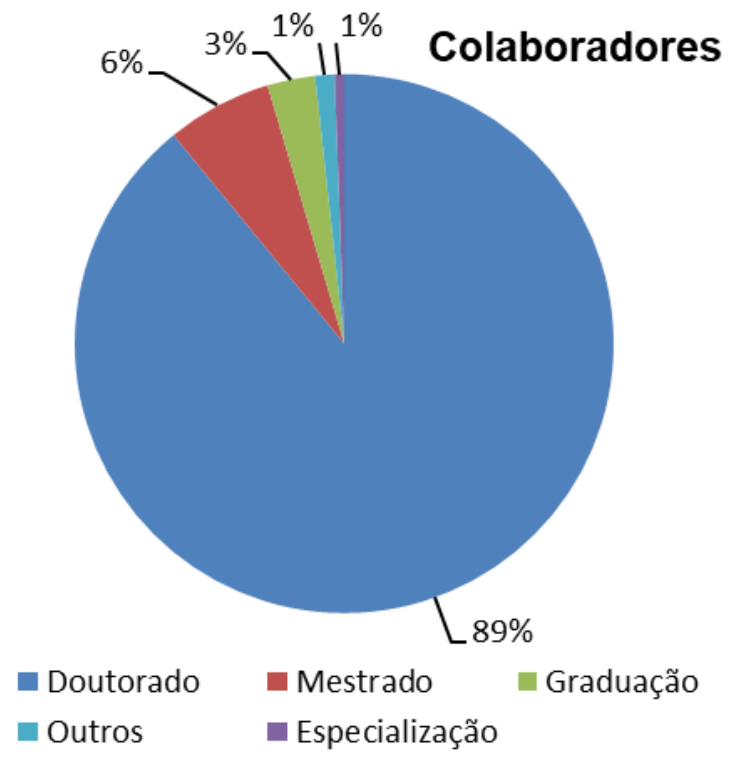

FONTE: Elaborada pelo autor.

Destaca-se a grande participação dos estudantes de graduação na composição dos grupos de pesquisa da UFMG.Isso reforça a importância dada pela Instituição no caráter formativo de seus discentes, também no que tange à pesquisa, impulsionados, possivelmente, pelos projetos de iniciação científica, seja por meio de bolsas ou voluntários.

Finalizando a análise dos recursos humanos dos grupos de pesquisa da UFMG, cabe destacar um aspecto muito importante, que é o dos participantes, de acordo com o gênero. Neste aspecto, o perfil da UFMG caminha alinhado ao dobrasileiro. Conforme demonstrado na Figura 22, entre: a) os estudantes, em que $61 \%$ são mulheres e $39 \%$ homens; b) os pesquisadores, em que $50,44 \%$ são homens e $49,56 \%$ são mulheres; c) os técnicos, em que $68 \%$ são mulheres e $32 \%$ são homens; e d) os colaboradores estrangeiros, pois $67 \%$ são homens e $32 \%$ são mulheres. Verifica-se grande destaque quantitativo para as mulheres quanto aos estudantes e aos técnicos, havendo praticamente um empate no que diz respeito aos pesquisadores e um destaque para os homens, no que diz respeito aos colaboradores estrangeiros. 
Figura 22 - Percentual de membros dos grupos de pesquisa por gênero (Censo, 2016) - UFMG.

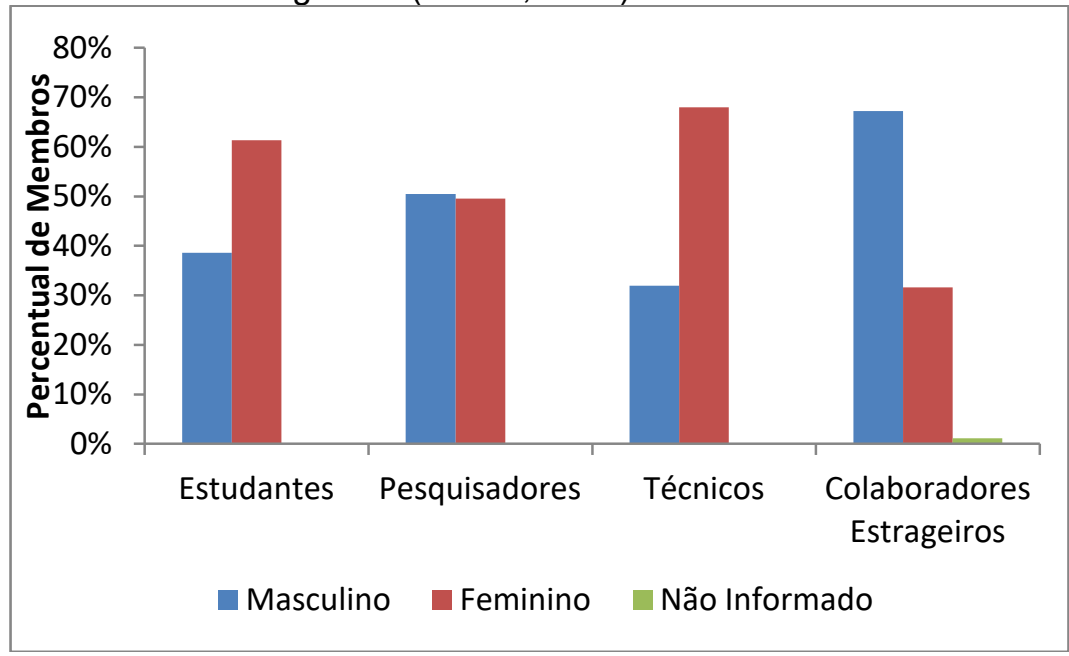

FONTE: Elaborada pelo autor.

\section{CONCLUSÃO}

Os grupos de pesquisa vêm ganhando cada vez mais importância no processo de geração, desenvolvimento e difusão de conhecimentos científicos, tecnológicos e culturais. Além disso, fornecemsuporte intelectual e estrutural, que possibilitam a qualificação das pesquisas e potencializam a geração de novos conhecimentos.

A partir dos resultados descritos e analisados, é possível, além de ter um panorama amplo do perfil dos grupos de pesquisa brasileiros, mapear e definir o perfil da UFMG. Estes devem ser certificados e atualizados no, apontando suas principais características.

Dessa forma, os dados indicam, em síntese, que o perfil dos grupos de pesquisa da UFMG, cadastrados no DGP, possui as seguintes características: cerca de $50 \%$ dos seus grupos estão concentrados nas áreas de Ciências Humanas, da Saúde e Sociais Aplicadas; cerca de $64 \%$ desenvolvem, entre uma e quatro linhas de pesquisa; $97 \%$ dos participantes são estudantes $(53 \%)$ e pesquisadores $(44 \%)$, sendo que a maioria destes é doutor $(82 \%)$ e daqueles é graduando (38\%); e que as mulheres são a grande maioria entre os estudantes e técnicos e estão empatadas com os homens entre os pesquisadores. 
É importante salientar, também, que está havendo uma mudança na política institucional dos grupos de pesquisa da UFMG, principalmente a partir de 2013, quando o PDI da Universidade trouxe uma série de objetivos, metas e ações nesse sentido, quando ganharam ainda mais força na versão subsequente do documento, em 2018. Através desses documentos,foipossível verificar que a UFMG tem se preocupado mais com o aspecto qualitativo em detrimento do quantitativo, uma vez que estimula o aumento na qualidade, na visibilidade e no impacto da produção, na internacionalização das colaborações e na melhoria da estrutura física dos grupos. Ao mesmo tempo, institui medidas como, por exemplo, a elaboração recente de documento normativo, no qual disciplina e torna mais rígida a criação de grupos de pesquisa no âmbito da UFMG.

Cabe ressaltar que, mesmo sendo um passo importante, referida mudança na política institucional ainda vem ocorrendo de forma incipiente. Os requisitos para a criação dos grupos, por exemplo, ainda que sejam mais rígidos do que as normas anteriores, continuam muito próximos daqueles minimamente exigidos pelo CNPq, sem demonstrar uma preocupação maior com a formação de um perfil desejável, ou mesmo com as atipicidades apresentadas pelo CNPq. É preciso continuar evoluindo no cumprimento das metas e ações estipuladas, para que os objetivos sejam consolidados e novos sejam traçados com o intuito de proporcionar, cada vez mais, melhores condições para o bom desempenho da pesquisa científica e da produção de conhecimento.

Desenhadoo perfil dos grupos de pesquisa da UFMG quanto ao recorte de dados analisados, é preciso ressaltar que o presente estudo possui algumas limitações, tais como: a) o recorde de dados ser limitado aos censos de 2000 - 2016 e a iminência de sair o censo 2018 com dados mais atuais; b) possuir dados apenas dos grupos certificados, o que exclui aqueles que estão cadastrados no DGP, mas estão na situação de não atualizados. Assim, espera-se que este estudo, mantendo seu aspecto informativo e formativo, possa despertar novas inquietações instigando a possibilidade da realização de novas investigações dentro desta temática, com recortes mais amplos, podendo utilizar-se dos dados do próximo censo, ou ainda, estudos com foco na produção científica dos grupos, estudos comparativos entre as variadas instituições de pesquisa, dentre várias outras possibilidades. 


\section{REFERÊNCIAS}

ARAÚJO, Ronaldo Ferreira. Os grupos de pesquisa em ciência, tecnologia e sociedade no Brasil. Revista Brasileira de Ciência, Tecnologia e Sociedade, São Carlos, v. 1, n. 1, p. 81-97, 2009.

BACKERS, V.M.S. et al. Grupos de pesquisa de educação em enfermagem da Região Sul do Brasil. Rev Gaúcha Enferm., Porto Alegre (RS), v.30, n.2, p.249-256, jun. 2009. Disponível em: <http://www.seer.ufrgs.br/Revista GauchadeEnfermagem/article/view/5054>. Acesso em: 11 nov. 2017.

CNPq. Diretório de Grupos de Pesquisa no Brasil. Glossário. 2018. Disponível em: <http://lattes.cnpq.br/web/dgp/glossario>. Acesso em: 27 jul. 2018.

. Diretório de Grupos de Pesquisa no Brasil. 2018. Disponível em: <http://lattes.cnpq.br/web/dgp/>. Acesso em: 22 mar. 2018.

ERDMANN, Alacoque Lorenzini; LANZONI, Gabriela Marcellino de Melo. Características dos grupos de pesquisa da enfermagem brasileira certificados pelo CNPq de 2005 a 2007. Esc. Anna Nery, Rio de Janeiro, v.12, n.2, p.316-322, jun. 2008. Disponível em: <http://www.scielo.br/scielo. php?script=sci_arttext\&pid=S1414-81452008000200018>. Acesso em: 03 nov. 2017. http://dx.doi.org/10.1590/S1414-81452008000200018.

MARAFON, Glaucio Jose. A importância dos grupos de pesquisa na formação dos profissionais de geografia agrária: a experiência do NEGEF. Campo - Território: Revista de Geografia Agrária, Minas Gerais, v.3, n.5, p.284-290, fev. 2008. Disponível em: <http://www.seer.ufu.br/index.php/ campoterritorio/article/view/11832> Acesso em: 19 out. 2018.

RAPINI, Márcia Siqueira. O Diretório dos Grupos de Pesquisa do CNPq e a interação universidade-empresa no Brasil: uma proposta metodológica de investigação. Rev. econ. contemp. Rio de Janeiro, v.11, n.1, p.99-117, abr. 2007. Disponivel em: <http://www.scielo.br/scielo.php?script=sci_arttext \&pid=S1415-98482007000100004>. Acesso em: 25 jul. 2018. http://dx.doi.org/10.1590/S1415-98482007000100004.

UNIVERSIDADE FEDERAL DE MINAS GERAIS. Conselho de Ensino, Pesquisa e Extensão. Resolução $n^{\circ}$ 02, de 09 de abril de 2019. Boletim [da] Universidade Federal de Minas Gerais, Belo Horizonte, ano 45,n. 2058, 13 maio 2019. Disponível em: <https://www.ufmg.br/prpq/wp-content/ uploads/2019/05/Resolucao-CEPE-02-2019.pdf>. Acesso em: 17 jul. 2019.

Projetos setoriais. In:

Plano de Desenvolvimento Institucional. Belo Horizonte: Universidade Federal de Minas Gerais, p. 113-128, 2013. Disponível em: <https://www.ufmg.br/dai/textos/PDI_ UFMG\%202013_2017.pdf>. Acesso em: 19 jul. 2019. 
Políticas acadêmicas. In:

Plano de Desenvolvimento

Institucional. Belo Horizonte: Universidade Federal de Minas Gerais, p. $72-$ 108, 2018. Disponível em: <https://www.ufmg.br/pdi/2018-2023/wp-content/ uploads/2019/03/PDI-revisado06032019 .pdf>. Acesso em: 19 jul. 2019.

Recebido em: 25/01/2019

Aceito em: 20/05/2019 